\title{
O ensino médico em São Paulo e a criação da Escola Paulista de Medicina
}

SILVA, M. R. B. da: 'O ensino médico em São Paulo e a criação da Escola Paulista de Medicina'.

História, Ciências, Saúde - Manguinhos, vol. VIII(3): 543-68, set.-dez. 2001.

Este artigo analisa a criação da Escola Paulista de Medicina (EPM), procurando discutir o papel desempenhado pelas ciências da saúde no processo de constituição da sociedade paulista, principalmente na década de 1930 . Os integrantes deste projeto fundamentaram suas ações na afirmação de atendimento a demandas por ensino superior e assistência médica, defendendo o saber especializado e a competência científica como suportes do desenvolvimento social, através da ciência, da educação e da saúde. A EPM foi criada com a participação de agentes e instituições extraacadêmicas que foram importantes para $\mathrm{o}$ processo de reconhecimento, oficial e social, e para a permanência da instituição. Sob este aspecto, foi fator decisivo a construção de um hospital de clínicas próprio, denominado Hospital São Paulo, no início da década de 1940. Este artigo também pretende contribuir para o entendimento das funções que a ciência assume na organização social,

\section{Medical Schools in} São Paulo and the creation of Escola Paulista de Medicina

Este artigo tem como base a dissertação de mestrado Construindo uma instituição: Escola Paulista de Medicina, 1933-1956 (Silva, 1998).

Márcia Regina Barros da Silva

Pesquisadora do Centro de História e Filosofia das Ciências da Saúde, Universidade de São Paulo

Rua Botucatu, 740, Museu Histórico

04023-900 São Paulo - SP Brasil mbarros.cehfi@epm.br constituição do campo médico em particular.

PALAVRAS-CHAVE: história da medicina, ensino superior, instituições, São Paulo.

SILVA, M. R. B. da: 'Medical Schools in São Paulo and the creation of Escola Paulista de Medicina'.

História, Ciências, Saúde - Manguinhos, vol. VIII(3): 543-68, Sept.-Dec. 2001.

The present article analyzes the foundation of Escola Paulista de Medicina (EPM) by discussing the role played by health sciences in the development of São Paulo's society, mainly in the 1930's. The participants in the project intended to meet the demands for universities and medical assistance by defending specialized knowledge and scientific competence as the base for social development through science, education and health. EPM was gradually created with the participation of non-academic agents and institutions that were important for the institution official and social recognition and permanence. Thus, in the beginning of the 1940's, it was decisive to build a hospital for the school - Hospital São Paulo. This article also intends to contribute to the understanding of the functions science has in social organization while dealing with the constituting processes of the specific medical field.

KEYWORDS: History of Medicine, Higher Education, institutions, São Paulo. 


\section{Introdução}

G ste artigo busca entender a criação da Escola Paulista de Medicina C (EPM) como uma instituição científica que desempenhou papel importante na constituição do campo médico em São Paulo, num momento, início da década de 1930, em que novas demandas procuravam inserir o país nos temas da educação, da saúde, da industrialização, do trabalho e da ciência (De Decca, 1997; Silva, 1998; Gomes, 1999).

Estas mudanças, por sua vez, já estavam presentes no discurso de parcelas da elite paulista que, desde o início da década de 1920, fomentavam discussões em torno da criação de universidades no país, mobilizando esforços na tentativa de atrelar o desenvolvimento socioeconômico que se instaurava em São Paulo às questões relativas ao desenvolvimento científico, tecnológico e cultural que também caracterizavam o período (Monarcha, 1989; Sevcenko, 1992; De Lorenzo, 1997).

A medicina esteve inserida neste conjunto de discussões através de propostas de instalação de escolas médicas, propostas estas que estavam intimamente ligadas a diversos aspectos da organização da atenção à saúde, tanto na questão da crescente urbanização da cidade com conseqüentes mudanças nos padrões de atendimento à população e instauração de novos modelos de saúde pública, quanto no estabelecimento e na produção de novos conhecimentos médicos, principalmente no campo da microbiologia (Almeida, 1998). A primeira proposta de instalação de uma academia de medicina e cirurgia foi feita em 1891 pela lei no19 de 24 de novembro (São Paulo, 1938), como parte de um plano do governo estadual de reorganização do ensino superior (Nadai, 1987).

São Paulo contava, desde meados do século XIX, com instituições voltadas para o cuidado com a saúde, a partir do agravamento das condições sanitárias na cidade, assim os primeiros serviços instalados pelo governo estadual estavam voltados para a higiene pública, como o Instituto Bacteriológico e o Instituto Vacinogêncio, ambos de 1892, e o Instituto Butantan, de 1901 (Benchimol e Teixeira, 1993; Gualtieri, 1994). Já a assistência era realizada basicamente pela Santa Casa da Misericórdia, instalada na capital desde 1825 e que em 1855 transferiu-se para nova sede (Carneiro, 1986), mesmo momento em que começaram a ser criadas associações mutualistas, como, por exemplo, a Beneficência Portuguesa, em 1850.

Neste período, houve um crescimento de atividades direcionadas ao debate sobre o campo médico, como a tentativa de organização de um congresso médico em 1878; a criação, em 1888, da Sociedade Médico-Cirúrgica de São Paulo, extinta em 1891 e recriada em 1895 como Sociedade de Medicina e Cirurgia de São Paulo; e a criação do primeiro periódico médico paulista em 1898, a Revista Médica de 
São Paulo; além da própria implantação do Serviço Sanitário do Estado de São Paulo em 1892, quando se consubstanciou uma política de saúde impulsionada, principalmente, pelo aumento do número de imigrantes para a agricultura paulista (Ribeiro, 1993; Tellarolli Jr., 1996; Hochman, 1998).

\section{Tentativas de instalação da primeira escola médica em São Paulo}

Apesar da lei de novembro de 1891, a verba aprovada para a instalação da Academia de Medicina foi suprimida por projeto do deputado Rivadávia Corrêa, em 1892. Em 1893, o secretário dos Negócios do Interior, Cesário Motta Júnior, em relatório ao presidente do Estado insistia na necessidade de instalação da Academia de Medicina, mas, apesar de ter sido destinada uma verba no orçamento de 1894-95, esta também foi retirada (Nadai, 1987).

Em 1896, após a criação da Sociedade de Medicina e Cirurgia de São Paulo, foi criada uma comissão, chefiada por Luiz Pereira Barreto, para elaborar um plano de ensino para a nova faculdade, mas divergências entre os integrantes do grupo definiram a apresentação de dois projetos distintos, que terminaram por não ser apreciados pelo congresso estadual ('Escola de Medicina', OESP, 10.3.1896; 'Não chegaram a accordo', idem, 11.3.1896; 'Desacordo sobre organização', ibidem, 12.3.1896).

Em 1900, a Sociedade de Medicina e Cirurgia de São Paulo propôs a instalação da faculdade junto a sua policlínica, criando estatutos e designando nomes para as diferentes cadeiras, mas o projeto não recebeu verba e a idéia foi abandonada ('Faculdade de Medicina', Revista Médica de São Paulo, 15.9.1900, p. 210).

Com a criação da Escola Livre de Farmácia, em outubro de 1898, particular mas subsidiada pelo governo estadual desde seu início, que em 1902 passou a ser responsável pelos cursos de parteiras e dentistas, recebendo o nome de Escola Livre de Farmácia, Odontologia e Obstetrícia, foi cogitada a instalação do curso médico. A partir de 1910, esta proposta passou a ser discutida mais seriamente, ao mesmo tempo que foi veementemente rechaçada pelos líderes da comunidade médica paulista e perdeu força.

A disputa convergiu para a busca de legitimação profissional do médico em face a outros profissionais da saúde, em especial o farmacêutico, como fica patente na fala de Rubião Meira (1913, p. 85), eminente clínico da Santa Casa:

se faz mister que na classe médica de S. Paulo se faça ouvir protesto solenne contra o modo pelo qual se vai erguer a Faculdade de Medicina ... farmacêuticos não podem entrar, por mais que seja a sua ilustração, como no caso, em congregação de Faculdade de 
Medicina, constituírem-se professores de futuros médicos, julgarem-nos em defesa de teses, com os mesmos direitos e as mesmas prerrogativas que a lei concede aos doutores em medicina.

Após a aprovação em 1911, da Lei Rivadávia Corrêa, que instituiu o ensino livre e possibilitou a criação de escolas particulares, foram fundadas instituições que ministravam diversos cursos, entre eles o de medicina.

A instituição de maior importância neste processo, pois foi a única que de fato contabilizou nomes importantes da medicina paulista em seu curso, foi a primeira Universidade de São Paulo (Sadi e Freitas, 1995), criada em novembro de 1911 pelo médico Eduardo Augusto Ribeiro Guimarães (Valle, 1961; Valle e Guimarães, 1961), que possuía diversas faculdades entre elas a de medicina. Esta primeira faculdade era constituída por um Instituto Anatômico, localizado no Cemitério do Araça, em terreno doado pela prefeitura, uma Policlínica e um Hospital Universitário, localizado no Brás e mantido por uma fundação criada especialmente para este fim, o Instituto Pereira Barreto. Entre os professores do curso estavam nomes de grande prestígio, como Vital Brazil, na cadeira de microbiologia; o próprio Eduardo Guimarães, reitor da Universidade e professor de patologia; Ulysses Paranhos, na cadeira de clínica médica; Alberto Seabra, de higiene; Luiz Philippe Baeta Neves, de ginecologia; Antonio Carini, de anatomia e histologia; Franco da Rocha de neurologia e psiquiatria, entre outros.

O médico Arnaldo Vieira de Carvalho foi convidado para lecionar na faculdade, mas recusou o convite. Na época, foi chamado para instalar e dirigir a Faculdade de Medicina e Cirurgia de São Paulo (FMCSP), a partir da lei no 1.357 de 19 de dezembro de 1912, que aprovou a regulamentação anterior e garantiu verbas para a escola oficial.

A faculdade de medicina particular passou, a partir da criação da faculdade oficial, a sofrer graves perdas de alunos e professores; e embora os diplomas de seu curso fossem válidos junto ao governo federal, precisariam ser reconhecidos pelos serviços de saúde do estado para permitirem o exercício da medicina, o que não ocorria devido a diferenças na interpretação da lei do ensino superior (Teixeira, 1995). Estas dificuldades e pressões do meio médico sobre a lei que instituiu o ensino livre, desencadearam uma discussão sobre a falta de qualidade do ensino oferecido pelas instituições particulares.

Embora houvesse posições a favor do ensino particular, como o artigo veiculado no Correio Paulistano ('A questão do ensino'), elas não eram maioria: "A instrução superior, porém, isto é, aquela que dá aos indivíduos os privilégios das profissões liberais, essa não pode ser gratuita e aqueles que a pedem ao estado, devem pagar bem e em proporção com o que apprendem" (Medeiros, 11.8.1910). 
Em decorrência da falta de inspeção federal e sob a influência de outros critérios que intervinham desfavoravelmente na aceitação da proposta de criação de uma escola médica em São Paulo - que diziam respeito ao relacionamento mais próximo entre ensino e pesquisa, entre saúde e serviços públicos e entre organização profissional e carreira docente, atividades que não foram priorizadas na organização da faculdade particular — este primeiro curso de medicina foi encerrado em 1917.

A importância das considerações feitas acima pode ser percebida desde as primeiras discussões em torno da criação de uma faculdade de medicina em São Paulo, quando se utilizava a argumentação da produção de conhecimento científico por meio da pesquisa experimental como forma de entender as especificidades do Brasil e formar pessoal competente para trabalhar no interior do pais. Elza Nadai, apresentando relatório do secretário dos Negócios do Interior, Cesário Motta Jr., faz esta avaliação:

Cesário Motta Jr., em relatório de 1893, declarava a necessidade de se instalar a Faculdade de Medicina e, para isso, apresentava várias razões. Em primeiro lugar, preocupava-se com o estudo das "moléstias peculiares" do pais, em geral desconhecidas, em segundo, com a ausência, "mormente no interior", de médicos, farmacêuticos e obstetras "competentes". A freqüência com que utilizava o argumento que insistia na necessidade de a medicina ser compatível com as condições naturais do país denotava preocupação com o seu caráter experimental. Do estudo da fauna e da flora deveria resultar um número expressivo de medicamentos e o maior conhecimento do clima conduziria, necessariamente, a melhor e mais preciso diagnóstico.

A integração entre ensino e pesquisa era apontada por diversos médicos e amparada pela imprensa. Em uma série de artigos que tratavam da história da medicina, oficiava-se esta opinião (Bertarelli, 1910).

De alguns anos aqui a ciência experimental, fundamento da medicina, abandonou os seus trajos modestos. A fidalguia não é simplesmente exigência nascida no cérebro dos sacerdotes de Minerva, é uma necessidade prática ... Ou a ciência tem instalações dignas de sua missão ou melhor é não tê-la, guardá-la para o futuro e fazê-la então bem-feita ... Obra coletiva a escola de medicina, como fruto de todos, deve ser digna da coletividade. E quando a coletividade é São Paulo, com suas tradições de cultura, duplos são os deveres e mais alta a dignidade a tutelar.

Após a criação da faculdade particular, a oficial foi rapidamente instalada com o nome de Faculdade de Medicina e Cirurgia de São 
Esta é a perspectiva da minha atual tese de doutorado, em que pretendo analisar as atividades de pesquisa no ensino médico paulista.

"Assim, ao contrário do que tem sido reafirmado pelos estudos recentes, a introdução da investigação científica ligada à tarefa docente foi proposta por segmentos das elites médica da Corte afinados com o movimento que mudava a face da medicina européia, e reivindicada como condição indispensável ao desenvolvimento profissional" (Edler, 1992, p. 28).
Paulo (FMCSP), pelo decreto no 2.344 de 21 de janeiro de 1913, que ampliou os decretos anteriores. Arnaldo Vieira de Carvalho (Guimarães, s. d.), que tinha a perspectiva da ligação entre pesquisa e ensino na sua própria experiência profissional como diretor do Instituto Vacinogênico em 1892, integrante da Sociedade de Medicina e Cirurgia de São Paulo e diretor clínico do Hospital da Santa Casa da Misericórdia, cargo que ocupava desde 1894, também enfatizou o trabalho de pesquisa, aulas práticas em laboratório e a prática clínica em serviços hospitalares para os alunos do curso médico na regulamentação criada.

Este tipo de preocupação esteve presente ainda durante a contratação de professores para a faculdade oficial, quando se insistia na competência científica para a escolha do profissional, procedimento que estabeleceu um vínculo entre a atividade de ensino e a pesquisa clínica e/ou experimental também desenvolvida pela maioria dos docentes contratados, exercida principalmente nos laboratórios e ambulatórios da Santa Casa da Misericórdia de São Paulo onde eram realizadas as atividades práticas do curso médico. ${ }^{1}$

Para a faculdade oficial, a procura por vagas foi grande, houve um total de 180 matriculados no primeiro ano, já que a mesma admitia, além dos que fossem aprovados no vestibular, alunos com diplomas de outros cursos superiores e diplomados em ginásios oficiais do estado.

Assim é possível verificar que em torno da FMCSP foi construída uma unanimidade que excluía outros tipos de instituições de ensino médico que não fossem aquelas inseridas nos padrões de um determinado quadro científico. Se, como afirma Edler (1992), o ensino na Faculdade de Medicina do Rio de Janeiro, desde a reforma de 1884, já era regido por novas visões de saber médico embasadas na pesquisa experimental, ${ }^{2}$ em São Paulo, embora estas visões já estivessem consideravelmente estabelecidas no campo médico como um todo, no ensino isto ainda não havia sido traduzido até pelo menos 1913.

Com a criação da FMCSP, foram importantes os arranjos que compuseram um quadro de associação entre ensino e pesquisa, quer experimental, quer clínica, que equilibraram por um certo período as questões em torno da eficiência que os médicos e outros envolvidos pretendiam para o ensino.

\section{As reformas na faculdade oficial}

Em 1924, houve a primeira reorganização da FMCSP, que teve o nome de Reforma Pedro Dias (leis n ${ }^{\text {os }} 2.016$ de 26.12.1924 e n².124 de 30.12.1925), diretor da faculdade na época. Esta reforma modificou substancialmente a organização do ensino com o fim de adequá-lo às prerrogativas da norte-americana Fundação Rockefeller para o recebimento de auxílio financeiro para ampliação das suas instalações. Instituiu-se a limitação do número de matrículas, o chamado numerus 
clausus, quando a faculdade passou a funcionar regularmente com cinqüenta alunos; modificou-se ainda a carga horária dos docentes com a instalação do regime de tempo integral; impôs-se a reorganização das disciplinas básicas com maior ênfase nos trabalhos experimentais; foi introduzida a figura do docente-livre; além da alteração do nome para Faculdade de Medicina de São Paulo (FMSP) (Marinho, 1993).

Em dezembro de 1928 (Lei ${ }^{\circ} 2.355$ ), nova reforma alterou a estrutura didática do curso médico, que passou a ser organizado com os seus três primeiros anos como de ensino fundamental e os três últimos como curso especializado, mais uma vez sendo enfatizada a limitação do número de vagas conforme as "possibilidades do ensino" (FMSP, 1938).

Uma nova modificação obrigou a FMSP a se adaptar ás diretrizes definidas pelo governo federal com a Reforma Francisco Campos, destinada a reorganizar todo o ensino superior, decreto $\mathrm{n}^{\circ} 5.351$ de 16.1.1932 (São Paulo, 1937), após as alterações políticas que se efetivaram a partir de 1930 com a ascensão e a centralização administrativa do governo Vargas (Gomes, 2000).

No tocante ao acesso ao ensino, houve a implantação de um curso preliminar ao primeiro ano do curso médico, denominado curso pré-médico, com duração de um ano, que deveria servir de "adaptação didática" ao curso superior, sendo obrigatório para ingresso no primeiro ano médico, dependendo também de classificação nos exames vestibulares, que teria, na prática, a função de frear o acesso aos cursos da faculdade, impondo mais uma dificuldade ao ingresso, pois a aprovação ao curso médico dependeria também da aprovação nas matérias do curso preliminar.

A reforma definiu pormenorizadamente a organização interna da Faculdade de Medicina, interferindo em sua estrutura didática e administrativa, regulando a composição do corpo docente, detalhando a realização de concursos, provas e aprovações, o tipo de regime escolar, a instalação e organização de cursos de aperfeiçoamento, entre outras definições. Como conseqüência imediata, foi dado maior poder à congregação, com o fortalecimento da figura do professor catedrático e a eliminação de qualquer oposição na organização hierárquica dentro da faculdade, extinguindo-se o cargo de livredocente e subordinando os assistentes e a organização das disciplinas ao catedrático.

Esta reforma provocou descontentamento junto aos alunos, que em artigo na imprensa mostraram discordâncias com as novas determinações, que, para eles, traziam várias desvantagens. Na opinião dos alunos, a maior restrição de notas e de freqüência, o aumento de carga horária e a grande concentração de disciplinas redundaram na cristalização de diretrizes excessivamente rígidas no ambiente intelectual da faculdade: "esta reforma feita pelos catedráticos parece olhar demasiadamente para os catedráticos ... tendendo a transformar o aluno num autômato sem a menor liberdade de ação, diminuindo assim a iniciativa e o 
estímulo individual" ('A reforma da Faculdade de Medicina ...', Folha da Noite, 1932).

No ano da reforma, 1932, o vestibular serviria para o ingresso tanto no curso pré-médico quanto no primeiro ano do curso médico. Os primeiros cinqüenta classificados entrariam no curso médico e os cinqüenta restantes no curso preliminar. Esta reforma acenava, por outro lado, com a 'possibilidade' de aumento no número de vagas do curso pré-médico, prevendo seu desdobramento em dois anos letivos, para atender as disposições do regime federal de ensino, que também previa os cursos preliminares em dois anos.

A partir desta brecha e dos descontentamentos originados com tais mudanças, os excedentes do vestibular do ano seguinte (1933), passaram a reivindicar uma reorganização nos cursos oferecidos pela faculdade. Este procedimento serviu também para aglutinar e catalisar os esforços de um grupo de médicos e de professores assistentes da FMSP que repensavam os espaços de exercício de suas atividades profissionais naquele momento.

\section{O 'caso dos excedentes' e a fundação da Escola Paulista de Medicina}

O vestibular de 1933 previa exame somente para o curso pré-médico, já que o primeiro ano do curso médico seria preenchido pelos aprovados no curso preliminar instaurado no ano anterior. Neste vestibular, além dos cinqüenta alunos aprovados, outros 119 obtiveram a nota mínima exigida, mas não obtiveram classificação que lhes permitisse matrícula no curso pré-médico. Os estudantes excedentes iniciaram várias reuniões acompanhadas pela imprensa, principalmente pelos jornais do grupo Folha, em que questionavam os critério de classificação da faculdade (Faculdade de Medicina de São Paulo, 1926 a 1933; 'Os exames vestibulares na Faculdade de Medicina', Folha da Noite, 27.3.33).

Diante das novas instalações, inauguradas em 1931 para abrigar a Faculdade de Medicina na av. Dr. Arnaldo, com verba da Fundação Rockefeller, e das recentes reorganizações internas do curso médico, os estudantes passaram a reivindicar o aumento de vagas no curso pré-médico, requerendo a criação do segundo pré-médico, como forma de aumentar também o número de admitidos na faculdade ('Muitos candidatos para poucas vagas', Folha da Noite, 28.3.1933; 'Os candidatos do curso pré-medico... ', Folha da Noite, 31.3.33; 'A questão do curso pré-medico', Folha da Noite, 1.4.1933).

No início, este movimento não tinha a intenção de propor qualquer outra solução que não fosse o ingresso deste grupo no curso da FMSP. A argumentação utilizada baseou-se em discussões sobre a insuficiência do número de médicos formados no estado para o atendimento à saúde, tida por todos (médicos, estudantes e imprensa) 
como conseqüência direta do baixo número de vagas oferecidas pelo ensino público oficial:

Com efeito, sob todos os pontos de vista, parecem-nos justas as nossas pretensões: o ensino superior aqui ainda é bem deficiente. Formamos cinqüenta médicos por ano, para um acréscimo de duzentos mil habitantes, enquanto que a Itália, para um argumento de quatro milhões de almas, forma mais de 1.300! A nossa população universitária se traduz por quatro acadêmicos para dez mil habitantes. ... Vejamos, agora o caso paulista: o jovem que quer estudar em São Paulo, na melhor escola do país, encontra suas portas trancadas. E, enquanto isto se dá, entram anualmente no Estado de São Paulo duzentos médicos, que aqui vêm constituir clínica ('O que pretendem os alunos do curso prémédico...' Folha da Noite, 6.4.33).

No mesmo período da divulgação do caso dos excedentes, o médico Octávio de Carvalho reuniu um grupo de outros médicos interessados no tema do ensino e juntos passaram a tentar definir rumos e medidas necessárias para a organização de uma nova escola médica em São Paulo.

Octávio de Carvalho era um conceituado médico clínico em São Paulo, formado pela Faculdade de Medicina do Rio de Janeiro em 1915, tendo sido interno do médico Miguel Pereira, ganhando com sua tese de doutoramento A febre typhoide á luz dos conbecimentos modernos o prêmio Torres Homem no mesmo ano, trabalho este realizado no Instituto de Manguinhos. Além de ter feito estágios no Instituto Bacteriológico e no Hospital de Isolamento em São Paulo, estagiou também na Clínica Mayo nos Estados Unidos e no Charité de Berlim.

Filho do senador da República Theodoro Dias de Carvalho Júnior, transferiu-se para São Paulo em fins de 1916, onde trabalhou na Faculdade de Medicina como interno do serviço do prof. Rubião Meira, e partiu para a clínica particular após dois anos de estudos na Europa. Teve papel fundamental na iniciativa da nova escola médica paulista, indicando os rumos iniciais do projeto e organizando reuniões preparatório junto aos interessados:

Octávio de Carvalho expôs os fins da reunião esclarecendo as razões de ordem didática, científica e social que a justificavam. Expôs as simpatias que a idéia dessa criação encontrou. Das pessoas ouvidas a esse respeito, inclusive professores da Faculdade de Medicina de São Paulo, e as facilidades de ordem material que parecem amparar essa idéia - simpatias e facilidades, essas inspiradas sobre consideração da insuficiência quantitativa do ensino ministrado pela Faculdade de Medicina de São Paulo. Fez ver os benefícios de toda ordem que a fundação de uma nova Escola Medica traria 
3 Além destes, assinaram o manifesto de fundação: Alípio Corrêa Neto, Álvaro Guimarães Filho, Álvaro Lemos Torres, Antônio Bernardes de Oliveira, Antônio de Almeida Júnior, Antônio Prudente, Archimede Bussaca, Carlos Fernandes, Décio de Queiroz Telles, Domingos Define, Dorival Macedo Cardoso, Eduardo Ribeiro, Fausto Guerner, Felício Cintra do Prado, Felipe Figliolini, Flávio da Fonseca, Jairo Ramos, João Moreira da Rocha, José Ignácio Lobo, José Maria de Freitas, José Medina, Luiz Cintra do Prado, Marcos Lindemberg, Nicolau Rossetti, Olivério Mário de Oliveira Pinto, Paulo Mangabeira Albernaz, Pedro de Alcântara e Rodolfo de Freitas. a São Paulo, deixando bem claro que o espírito da nova fundação seria o da colaboração mais cordial com a Faculdade de Medicina na tarefa do ensino médico em São Paulo (EPM - AAGE, 22.3.1933, f. 2).

Apontando o caso dos excedentes da FMSP como um episódio revelador da crescente demanda por vagas no ensino médico, e com isto tentando demonstrar a viabilidade e as vantagens da participação no novo empreendimento, Octávio de Carvalho e alguns outros médicos começaram a participar das reuniões dos estudantes que se realizavam no Parque Trianon, na avenida Paulista.

Foi neste momento que o noticiário sobre a questão dos excedentes passou a sofrer alterações em que se apontava uma mudança de atitude quanto à reivindicação dos estudantes: a partir desta data começaram a surgir notícias sobre a criação de uma nova escola médica em São Paulo e em $1^{\circ}$ de junho de 1933 foi lançado o manifesto de fundação da Escola Paulista de Medicina (EPM) na imprensa local.

A nova escola foi criada como instituição particular, sem fins lucrativos, cujo patrimônio seria constituído por cotas pagas pelos fundadores e pelas mensalidades dos alunos a serem matriculados. A escola aparecia com algumas vantagens imediatas no confronto com a faculdade oficial: os alunos ingressavam diretamente no $1^{\circ}$ ano do curso médico, sem a obrigatoriedade do curso pré-médico, havia maior número de vagas, fixadas inicialmente em duzentas, além da menor concorrência em comparação com os exames para a FMSP.

Vários médicos e cientistas de renome nacional e internacional participaram da criação da EPM, entre eles podemos citar Henrique da Rocha e Lima, que trabalhou no Instituto Oswaldo Cruz (IOC) de 1901 a 1909, quando foi lecionar na Universidade de Iena na Alemanha, sendo diretor do Instituto Biológico de São Paulo em 1932; Afrânio do Amaral, diretor do Instituto Butantan por duas vezes, de 1919 a 1920 e de 1927 a 1938, antes dirigindo o Antivenin Institute of America e lecionando na Escola de Higiene da Universidade de Harvard; Otto Bier, pesquisador do Instituto Biológico; e Antônio Carlos Pacheco e Silva, diretor do Hospital Juqueri de 1923 a 1930 e ligado à criação do Instituto de Organização Racional do Trabalho (Idort), sendo seu primeiro presidente ${ }^{3}$.

A principal argumentação dos fundadores para a criação de uma nova escola médica era a que apontava a EPM como fator de apoio à "união da família paulista", pois até então os excedentes dos vestibulares da faculdade oficial, ficando 'impedidos' de estudar em São Paulo pela insuficiência do número de vagas, 'emigravam' para outros estados em busca de cursos particulares, gerando a separação do convívio familiar e a evasão de rendas do estado ('Manifesto de fundação...', Folha da Noite, 1.6.1933). Longe de se remeterem a questões 
4 As disciplinas do curso médico neste período eram: na $1^{\text {a }}$ série, anatomia; histologia e embriologia; na $2^{\mathrm{a}}$ série, física biológica; fisiologia e química fisiológica; na $3^{a}$ série, farmacologia; microbiologia; parasitologia e patologia geral; na $4^{\mathrm{a}}$ série, anatomia e fisiologia patológica; clínica propedêutica cirúrgica; clínica propedêutica médica; na $5^{a}$ série, clínica cirúrgica; clínica médica; clínica urológica; higiene; medicina legal; moléstias tropicais infecciosas; terapêutica clínica; na $6^{a}$ série, clínica ginecológica; clínica médica; clínica neurológica; clínica obstétrica; clínica oftalmológica; clínica ortopédica; clínica otorrinolaringológica; clínica pediátrica e higiene infantil e clínica psiquiátrica. exclusivamente relacionadas ao ensino, estes médicos estavam alinhando diferentes perspectivas que indicavam também a preocupação de influírem nos destinos do profissional e da sua formação em face das transformações por que passava a sociedade paulista naquele momento.

\section{Trajetórias profissionais e pessoais}

Os fundadores, que mais tarde viriam compor também o primeiro núcleo de docentes da EPM, foram sendo convidados a participar do projeto em função de seus interesses na carreira docente, e ainda de acordo com suas especialidades, pois verifica-se que entre eles houve apenas um especialista de cada área que compunha o quadro das disciplinas do curso médico. ${ }^{4}$ Apesar disso, é importante notar que os critérios utilizados não se restringiram a estes fatores: afinidades de concepções sobre ensino, medicina e ciência foram fundamentais para este agrupamento.

Grosso modo havia três grandes conjuntos de atividades a que os participantes do grupo se filiavam. Primeiro, o dos médicos que já se encontravam envolvidos com o ensino superior, lecionando como auxiliares na FMSP nas dependências da Santa Casa da Misericórdia, onde ocorriam as aulas clínicas do curso médico; segundo, o grupo dos que atuavam no atendimento clínico, principalmente nos serviços de saúde do estado; terceiro, o grupo dos médicos que se dedicavam às áreas básicas, atuando nos institutos de pesquisa de São Paulo.

A prática docente foi, sem sombra de dúvida, a área que agregou maior número de fundadores, já que a maioria deles trabalhou na FMSP em algum momento de suas carreiras. Esta instituição foi apontada, ainda que retoricamente, como responsável pelo "grande" impulso que tinha dado à medicina paulista, pois teria proporcionado um tal estado de "elevada propaganda da medicina como profissão" que fazia com que a própria faculdade fosse "insuficiente" para atender a totalidade das demandas criadas a partir de sua fundação (idem, 1.6.1933).

É importante perceber que em nenhum momento estes fundadores discutiram a qualidade do ensino ministrado na FMSP, muito pelo contrário, reforçavam a "importância" da continuidade de suas atividades, apontando a nova escola como um núcleo que estava sendo criado sob as mesmas bases intelectuais dos responsáveis pelas duas instituições de ensino médico criadas anteriormente na capital paulista.

Embora os fundadores da EPM afirmassem reiteradamente a importância da Faculdade de Medicina oficial, apontando apenas as dificuldades advindas com o escasso número de vagas para o curso médico e a insuficiência de atendimento hospitalar na cidade, estes temas apontam apenas parte da questão. Uma rápida análise dos nomes 
Um exemplo deste movimento foi $\mathrm{o}$ excedente Octaviano Alves de Lima Júnior, filho do proprietário dos jornais Folba da Noite e Folba da Manhã. Seu pai ao comprar os dois jornais "empastelados" na Revolução de 30, buscava apoio e procurava representar os agricultores paulistas. Transferindose para o comércio do café, sobretudo com o exterior, vinha de família descendente "dos primórdios da colonização, mas que não entraram no século $\mathrm{XX}$, em situação dominante" (Mota e Capelato, 1981, p. 57), permanecendo no jornal de 1931 a 1945 , foi além de comerciante de café, fazendeiro em Campinas até 1942 , comissário e exportador em Santos e representante do governo de São Paulo no escritório do Instituto do Café em Nova York. e sobrenomes dos estudantes inscritos no vestibular da nova escola apresenta um grande número de representantes de antigas elites empobrecidas, principalmente cafeicultoras, além de representantes da classe média. ${ }^{5}$

A principal argumentação dos estudantes para o ingresso na Faculdade de Medicina havia sido as dificuldades financeiras de mais um ano de estudos. Logo no primeiro ano do curso na EPM, em se tratando de uma escola paga, houve muitos pedidos de bolsas e descontos, além da desistência de alguns alunos por dificuldades no pagamento.

O grupo fundador, por seu lado, também possuía representantes de elites econômicas em busca de novas posições e neste aspecto o esforço em ocupar uma cátedra na FSMP, que representava uma posição profissional privilegiada no cenário paulista, entrava em choque com a vitaliciedade daqueles cargos, preenchidos em sua maioria pelos mesmos professores desde a fundação da faculdade, o que não propiciava que recém-formados, ou mesmo profissionais vindos de outras instituições, conseguissem concorrer a estas vagas (Albernaz, 1968).

Nesse sentido, a proibição da livre-docência pela reforma de 1932, que era uma forma paralela pela qual diversos médicos participavam do curso como professores, com aulas e atividades que não pertenciam à jurisdição exclusiva dos catedráticos, e que tinham caráter extracurricular, foi como uma deflagração de guerra entre os médicos que atuavam na FMSP.

Um exemplo das dificuldades deste processo foi o do médico Álvaro Lemos Torres, formado pela Faculdade de Medicina do Rio de Janeiro em 1907, que viria a ser, após Octávio de Carvalho, o segundo diretor da EPM, e que foi apontado mesmo por médicos da FMSP como um "plasmador de vocações, formador do espírito clínico, espécie de professor sem cátedra de muitas gerações de médicos" (Prado, 1954, p. 24), ou seja, amplamente reconhecido no meio médico mas não seu representante de fato, por não possuir uma cadeira na faculdade estadual (Corrêa Netto, 1939).

A trajetória de Torres demonstra seus constantes esforços para ingressar no corpo docente da FMSP. Assistente efetivo desde 1916 na cadeira de clínica médica do então catedrático Rubião Meira, em 1925 surgiu para ele a possibilidade de disputar uma vaga como professor, "a única oportunidade que durante todo esse tempo se lhe oferecera de competir a um concurso: foi a vaga de professor substituto da oitava seção de clínica médica que lha proporcionou" (Torres, 1937, p. 27).

Este concurso, porém, não foi aberto, pois a congregação alegou que todos os concursos estariam fechados até o fim da Reforma de 1924, que viria também a extinguir a referida vaga. Contudo, no mesmo período, outros três concursos foram abertos para catedrático das cadeiras de psiquiatria, moléstias nervosas e clínica obstétrica, e para 
6

Duas exceções podem ser apontadas porém apenas depois de criada a EPM, com os concursos de Alípio Corrêa Neto, em 1935 , para a cadeira de clínica cirúrgica, e de Antônio Carlos Pacheco e Silva, em 1936, para cadeira de clínica psiquiátrica (FMSP, 1991).

Já em 1907 o médico Alexandrino Pedroso, que virá a ser em 1919 um dos primeiros professores

concursados da FMCSP da cadeira da $4 a$ seção (histologia, microbiologia, anatomia e histologia patológica) viajou para os Estados Unidos, visitando o Instituto Rockefeller e o dr. Simon Flexner ('Visita ao Instituto Rockfeller...', Gazeta Clínica, 3.1909, p. 3). a vaga de clínica médica, que foi extinta, criando-se outra similar, a de patologia médica, ocupada pelo então diretor da faculdade, Pedro Dias da Silva. Quando esta também foi extinta pela reforma de 1932, mesmo colocado em disponibilidade, o professor conservou todas as prerrogativas e vencimentos do cargo (FMSP, 1938).

Como Lemos Torres, vários outros fundadores da EPM possuíam experiência docente, sendo mesmo catedráticos de instituições não médicas como nas áreas de medicina legal e psicopatologia forense da Faculdade de Direito, na qual lecionaram, respectivamente, Antônio Ferreira de Almeida Júnior e Antônio Carlos Pacheco e Silva, além de outros dedicados ao ensino secundário e a diversos tipos de preparatórios. Tal experiência, entretanto, não foi suficiente para que os fundadores fossem contratados como catedráticos da FMSP. ${ }^{6}$

O malogro dos projetos de acesso às vagas de catedráticos enfatizou a questão sobre a prática hospitalar como único ponto que, em teoria, diferenciava o curso da FMSP do curso da EPM. O grupo de professores responsáveis pelo ensino prático dos estudantes da FMSP nas instalações da Santa Casa da Misericórdia foi o que mais reivindicou a construção de um hospital dedicado especificamente ao ensino junto à nova escola médica (Torres, 1934). O hospital foi apresentado por estes médicos como o veículo que possibilitaria uma melhor condução do aprendizado da medicina e a resolução de vários problemas de saúde da população pobre. A concepção do grande hospital como o espaço propício para a intensificação do aprendizado profissional foi uma constante entre os médicos ligados ao ensino neste período.

Em 1910, havia sido publicado nos Estados Unidos o Relatório Flexner, ${ }^{7}$ que, a partir da análise da formação médica em 150 escolas dos Estados Unidos e Canadá, formulou uma proposta educativa para as instituições de ensino médico: "uma aprendizagem voltada para a prática concreta e para a pesquisa clínica, com níveis progressivos de ensino, uns pré-requisitos dos outros', esta proposta 'indicada para ser uniformemente adotada pelas escolas médicas' revolucionou o ensino médico norte-americano" (Gomes, 1992, p. 52), cuja ascensão se fazia notar no Brasil, por exemplo, com o estreitamento de relações com a Fundação Rockefeller. Todavia, não houve no Brasil até meados da década de 1930 nenhum hospitalescola criado especialmente para atender ao ensino, a não ser os hospitais que, em convênio com as instituições de ensino, cumpriam esta função.

A idéia de hospital que surgiu no discurso dos médicos da EPM apresentava uma função diferente dos antigos hospitais filantrópicos existentes, visava mais a organização do saber médico e de suas concepções não só entre os próprios médicos, mas também para a sociedade, pela uniformização dos serviços e ampliação dos meios de educação para a saúde, que integrada à idéia de escola médica foi 
referência constante nos discursos do grupo, até a fundação de seu hospital de clínicas em 1940:

O hospital, hoje, não é mais o estabelecimento fechado e independente, não é apenas um departamento médico; hoje é 'um instrumento especial de instrução de saúde pública, um verdadeiro centro de saúde', como diz W. Alter. Assim, os hospitais pequenos só são admissíveis quando estão subordinados hierarquicamente aos grandes hospitais. E esse, segundo Serrz-Bournet, 'deverão ser equipados de modo completo e situados de preferência nas grandes cidades, perto das faculdades e das escolas médicas; são centros de ensino, providos de todos os serviços da especialidade e concomitantemente centros principais de saúde (Torres, 1940, p. 5).

Esta mesma idéia pode ser vista também no discurso dos médicos ligados aos serviços do Instituto de Higiene, grupo para o qual a educação exerceria o papel de "adaptar o indivíduo ao meio social em que deve(rá) viver", permitindo que o médico, com toda sua "autoridade profissional", realizasse uma "grande obra de saneamento da espécie humana” (Guimarães Filho, 1926).

Vários fundadores estiveram ligados a diferentes instituições que também tinham propostas de desenvolver social e tecnicamente a sociedade, baseadas na educação e na pesquisa científica. Dois exemplos marcantes são a Escola Livre de Sociologia e Política (Micelli, 1989; Silva, 1994), cujos fundadores reivindicavam que o exercício da sociologia fosse uma forma de melhor conhecer a sociedade e seus componentes, através da pesquisa de campo de cunho sociológica ('A Escola Livre de Sociologia e Politica', Folha da Manhã, 4.6.1933; 'O êxito alcançado em S. Paulo...', Folha da Noite, 19.7.1933) e o Instituto de Organização Racional do Trabalho Idort (Antonacci, 1993) que, num sentido mais 'pragmático', abordava o conhecimento técnico sobre o trabalho como a melhor forma de organização da sociedade por meio do exercício da racionalidade técnica (Álvaro, 1937).

A idéia de educação preconizada por estes médicos e cientistas apontava o projeto de criação de uma nova escola médica em São Paulo como uma possibilidade de responder às "necessidades do meio social", para além da referência imediata da criação de vagas no curso superior de medicina (Carvalho, 1933, p. 1). O discurso construído pelo conjunto dos participantes da EPM, alicerçado na competência científica e na prática profissional, transformava a educação em mais um componente da saúde e, ao mesmo tempo, fazia da prática educacional médica uma maneira de impor formas de organização tanto dos serviços médicos quanto da sociedade para a qual estas atividades eram direcionadas. 
Por meio da perspectiva de fornecer serviços de atendimento hospitalar, que seriam alicerçados na competência científica dos médicos fundadores da EPM e da promessa de competência também para os formados pela instituição, introduzia-se o tema do hospital para o atendimento à população, com ênfase na possibilidade de auxílio para o desenvolvimento econômico e para a expansão da industrialização paulista:

... podemos ainda dizer que não somente à população pobre falta hospitais gerais em São Paulo. Também as classes menos favorecidas da sociedade dispensam, não obstante, os serviços totalmente gratuitos, os trabalhadores das grandes companhias, os associados das corporações de previdência, os empregados no comércio, os funcionários públicos, os estudantes - a esses também faltam hospitais em nosso meio, porque, quando doentes, lhes toca a alternativa: ou pagar preços desproporcionados ao seu padrão de ganho, ou aceitar o regime da vida em comum nas enfermarias de indigentes. É oportuno lembrar-se que os hospitais têm, ao lado do seu aspecto humanitário, uma função econômica especial em relação ao meio, pois não só abrigam os que padecem, como restituem rapidamente à sociedade os indivíduos que a moléstia temporariamente invalida ('Manifesto', Folha da Noite, 29.10.1933).

A questão da função pública da escola e do hospital foi outra perspectiva recorrente na etapa inicial de instalação da escola. Constantemente retomada, esta idéia procurava compatibilizar a iniciativa particular com a administração pública e o estado. Os fundadores definiam a EPM e o HSP como de "utilidade coletiva", determinando que eles estariam atendendo a demandas por vagas no ensino superior e por assistência à saúde, interagindo com os demais serviços paulistas, ressaltando sempre que possível o caráter "voluntário" da nova instituição para se adequar às normas vigentes (EPM, 31.5.1933), o que foi enfatizado sempre que possível:

O Hospital São Paulo aí está, capaz de cuidar do cidadão, desde o nascimento até a velhice, de cuidar da mulher grávida antes e depois do parto ... Q Quer dizer, o Hospital São Paulo corresponde exatamente ao conceito moderno de assistência hospitalar como centro coordenador da saúde. Mas as associações particulares, as irmandades não podem mais, sozinhas, arcar com as despesas decorrentes desta transformação, e competirá ao estado auxiliar a iniciativa particular (Torres, 1940, p. 5).

A tradição 'bandeirante' de São Paulo foi apontada como o elo entre a nova instituição e a sociedade. Enfatizava-se nos discursos dos fundadores da EPM a existência de todo um conjunto de ações em bases racionais e técnicas, nos quais os conceitos centrais de desenvolvimento e de modernização passariam a ser amplamente 
disseminados com a iniciativa da criação de mais uma escola médica na cidade. Em suma, por estes discursos, a sociedade então se reorganizava, estabelecendo-se sob o signo da ciência.

No discurso inaugural da EPM, o diretor destacava São Paulo como o local que possibilitava a existência de tais projetos:

\begin{abstract}
Sob os auspícios de cordialidade, de confiança perseverante na sua finalidade filantrópica, os professores da Escola Paulista de Medicina firmaram publicamente o pacto de honra de jamais abandonar o sagrado patrimônio, para melhor servir São Paulo, este orgulho, esta jóia, esta maravilha da civilização contemporânea, em cujo solo germinam e prosperam todas as sementes puras, em cujo ambiente florescem os grandes ideais, em cujo seio em tempo algum deixaram de frutificar os grandes empreendimentos (Carvalho, 1933, p. 6).
\end{abstract}

A ciência acabava por ser apresentada como o princípio que viria conduzir e orientar a criação da EPM, solucionando os maiores problemas paulistas, sociedade destinatária de todo o esforço do "conhecimento" em direção à "prosperidade", como resumiu Pacheco e Silva (1933) na aula inaugural: "Se já não há mais sertões insondáveis para transpor, cerca-nos a mais tenebrosa das selvas que é a da ciência, e para penetrá-la se exigem não menor esforço, dedicação e desprendimento dos empregados pelos nossos antepassados na conquista do desconhecido".

Esta aliança com a ciência sustentava-se além de tudo pela participação, entre os fundadores, do grupo de profissionais relacionados com os institutos de pesquisa experimental, principalmente Instituto Butantan e Instituto Biológico, mas também através de relações com outros institutos de pesquisas biomédicas do Brasil por meio de cursos e intercâmbios.

Tendo em comum o trabalho com a pesquisa básica, destes institutos migraram vários pesquisadores que se estabeleceram na EPM nos anos subseqüentes à sua fundação, principalmente nas áreas de química fisiológica, fisiologia e farmacologia, o que será importante para a constituição da nova escola por ser fonte de associação entre a pesquisa experimental e a carreira docente.

\title{
A instalação e consolidação da Escola Paulista de Medicina
}

O primeiro estatuto da EPM, de 27 de maio de 1933, enfatizou a consonância das atividades de ensino realizadas na instituição com as disposições adotadas nas demais instituições oficiais de ensino, sobretudo no que se referia ao caráter 'científico' destas atividades: "Art. 1 ... c. Estimular e desenvolver a investigação científica nos domínios de conhecimento próprios da medicina (EPM — Estatutos, 26.6.1933). 
Logo de início houve a concordância 'oficiosa', de acordo com o diretor Octávio de Carvalho, do Departamento Nacional de Educação, para que as aulas da EPM fossem iniciadas num período letivo distinto do estabelecido para as escolas superiores no país, tendo o primeiro ano do curso médico funcionado de 15 de julho de 1933 a fins de fevereiro de 1934, quando se iniciou o segundo ano letivo (EPM, 1933-39).

As cadeiras foram sendo instaladas à medida que os semestres letivos iam avançando. Além das instalações alugadas para as aulas, várias atividades foram sendo realizadas nos serviços dos professores responsáveis pelas diversas cátedras que compunham o curso, como aulas de oftalmologia no Ambulatório de Oftalmologia na Liberdade, aulas de terapêutica clínica na sede da Sociedade de Medicina e Cirurgia de São Paulo, aulas de doenças tropicais e infecciosas no Hospital de Isolamento, aulas de psiquiatria na sede da Assistência Geral a Psicopatas do Estado de São Paulo, entre outras.

Concentrando esforços na obtenção de recursos financeiros para a construção do hospital de clínicas e no reconhecimento oficial do curso pelo Ministério de Educação e Saúde Pública (MESP), a EPM foi intensificando as condições as quais creditava serem fundamentais para se diferenciar no cenário da educação médica em São Paula, investindo intensivamente nos pontos fracos de tais tradições, como, por exemplo, a questão do reconhecimento oficial do curso médico, que não ocorreu no caso da primeira Universidade de São Paulo.

Para obter o reconhecimento legal da instituição e sua equiparação à congênere federal como determinava a lei, a Faculdade de Medicina do Rio de Janeiro, e conseqüentemente o reconhecimento dos diplomas expedidos, era preciso requerer ao MESP a inspeção preliminar de seus cursos, que deveria ser efetuada pelo Conselho Nacional de Educação, através do Departamento Nacional de Educação.

Logo em 20 de julho de 1933, portanto nos primeiros dias de aula, a EPM já havia enviado requerimento pedindo a inspeção prévia, sendo o pedido deferido (EPM, 1933-41).

A escola foi reconhecida em outubro de 1935 e a inspeção permanente concedida (decreto $\mathrm{n}^{\circ} 403$ de 4 de novembro) por intervenção direta do relator do processo, Raul Leitão da Cunha, então reitor da Universidade do Brasil, chegando logo após a ministro da Educação e Saúde Pública. Naquele ano a escola completava dois anos de existência e mesmo não possuindo todas as séries do curso implantadas foi aceito o seu argumento de idoneidade científica, apesar de antes ter que adequar suas atividades em outros itens referentes à aquisição de material de laboratório, diminuição do número de vagas de duzentos para cem e registro dos seus professores junto ao Conselho Nacional de Educação (EPM, 5.10.1935). 
Hospital Humberto

I, também conhecido

como Hospital

Matarazzo, foi fundado

em 1o de janeiro de

1905 e pertencia à

Sociedade Italiana de

Beneficência. Ao

analisar a imigração

italiana de médicos

para o Brasil, Salles

(1997) ressalta a

importância do hospital

para a afirmação

profissional dos

médicos italianos,

principalmente na

pesquisa científica.

Neste hospital

trabalhou entre outros,

o médico italiano

Archimede Busacca,

oftalmologista do grupo

fundador da EPM, que

foi responsável

também pela criação

do periódico Folia

Clinica et Biologica.
O processo de reconhecimento da EPM pelo governo federal aponta para o entendimento em comum dos temas da ciência, da educação médica e da saúde, entre a escola e representantes de vários segmentos dos poderes públicos naquele período, coincidência de perspectivas que foi recorrente no desenvolvimento da EPM e que correspondia ao impacto das transformações que buscavam a subordinação das diversas vertentes da vida social à autoridade do estado.

O texto do parecer da Comissão de Educação é muito revelador neste sentido:

Como vê o conselho, a escola esforçou-se por cumprir o que lhe foi exigido, e informa sobre as condições em que pretende manter o ensino no ano próximo o que, tudo acha a comissão, foi feito de modo muito satisfatório, demonstrando boa fé e desejo de acertar, qualidades estas que, em condições idênticas, infelizmente, nem sempre é dado ao conselho verificar. Sem dúvida que o ideal para o ensino prático seria a sua individualização até o ponto de permitir verdadeira atividade do aluno, e para isso o ótimo seria que nos laboratórios dispusesse cada aluno de local e aparelhos próprios e no hospital de um leito, onde tivesse sempre um doente sob a sua imediata observação. São condições essas, entretanto, que não creio existam sempre em nosso país, particularmente para o ensino clínico, razão por que podemos admitir, maxime sob o regímem de inspeção preliminar, período de adaptação, condições como as acima citadas (EPM, set. 1935)

\section{A construção do Hospital São Paulo}

Previa-se desde o início do curso que as aulas práticas de medicina fossem realizadas provisoriamente em algum hospital da cidade. Octávio de Carvalho conseguiu então o empréstimo das enfermarias do Hospital Humberto I, mantido pelo industrial italiano conde Francisco Matarazzo e dirigido pelo médico Benjamin Rubbo (EPM, 9.3.1936, f. 79). ${ }^{8}$

A escola associou a construção do hospital com as falas correntes, principalmente na imprensa, sobre a insuficiência de assistência médica gratuita, tanto em São Paulo quanto em cidades limítrofes ao estado que também procuravam assistência na capital. Os argumentos eram que a assistência particular era muito mais numerosa e eficiente do que a assistência pública, mas que aquela não era acessível a todos.

Foram realizadas várias campanhas para angariar fundos para o hospital junto a particulares e a diversas instituições públicas através de contatos com prefeituras do interior do estado, apelos ao Conselho Administrativo da Caixa Econômica Federal de São Paulo, à Comissão de Finanças da Câmara Federal dos Deputados e mesmo à presidência da República (EPM, 3.12.1934; 5.7.1935, 1.2.1936). 
Nestes pedidos, os representantes da EPM procuravam criar vínculos entre os campos do ensino e da assistência e os poderes públicos, a fim de obter verbas e reconhecimento para o hospital, como pode ser visto em vários textos, como no memorial apresentado ao Ministro da Educação e Saúde Pública:

...fundada com a exclusiva finalidade de cooperar na atenuação de múltiplos problemas que atinentes ao ensino médico e à assistência hospitalar se vinham impondo como carecedores de solução ...Conhecida como é a grave deficiência hospitalar existente entre nós, onde o coeficiente de leitos é de apenas um leito para cada mil habitantes, torna-se desnecessário realçar o inestimável concurso que vem assim prestar a suplicante para toda a população deste estado e dos estados limítrofes, trazendo-lhes o real benefício de uma assistência hospitalar gratuita ..., porém não lhe compete, como entidade particular, montar e sustentar hospitais para indigentes, atribuições essas da competência do estado e da União, motivo pelo qual recorre aos poderes públicos (EPM, 25.7.1935).

Antes da construção do "grande Hospital São Paulo" com 12 andares planejados, foi construído um pavilhão, que funcionou como unidade inicial de atendimento e de aulas junto às novas instalações da EPM, que foi, contudo, substituído após a finalização da obra principal.

Após os pedidos de verbas foi concedida uma subvenção à EPM pelo MESP, assim como um grande empréstimo da Caixa Econômica Federal de São Paulo (CEFSP, 1933 a 1935), que, junto com donativos de particulares, permitiu o início da construção do Hospital São Paulo em setembro de 1937 e sua inauguração em meados de 1940.

O reconhecimento final da EPM foi concedido após a inauguração de parte do HSP, em maio de 1938, e após três anos de inspeção preliminar, a tempo de atender aos alunos formados na primeira turma de médicos, em dezembro do mesmo ano.

O apoio recebido pela EPM por diferentes níveis do governo, federal principalmente, assim como os diversos auxílios econômicos e subvenções que the foram concedidas, demonstram que havia uma identificação entre as premissas de educação e saúde expressas na criação da EPM e diversos setores da sociedade paulista, interessados na disseminação de um tipo específico de ensino médico, que contribuísse também para o atendimento à saúde e que estava sendo esboçado com a criação do Hospital São Paulo. 
9 Embora já estivesse planejada a criação de um curso de enfermagem em São Paulo desde 1922 (Nadai, 1987, p. 214), como um projeto aprovado na Câmara do Deputados para a criação de um curso prático de enfermagem para o Serviço de Tracoma, uma escola de enfermagem estadual somente foi criada em 31 de outubro de 1942, pelo decreto lei 13.040, como parte integrante da USP (Lacaz e Mazzieri, 1995).

\section{A EPM sob nova direção}

Após o reconhecimento oficial do curso, o primeiro diretor Octávio de Carvalho foi substituído pelo também professor de clínica médica, Álvaro Lemos Torres, que teve como vice-diretor o professor de clínica obstétrica, Álvaro Guimarães Filho.

Com a finalização dos trabalhos para a instalação de todas as séries do curso médico e a construção já adiantada do Hospital São Paulo, a segunda diretoria concentrou esforços na criação de novos cursos e na ampliação das instalações da escola e dos serviços de assistência.

O segundo curso criado neste período foi o de enfermagem, que começou a funcionar em 25 de fevereiro de 1939, juntamente com um curso de enfermagem obstétrica (EPE, 1939 a 1961).?

No mesmo período, foi criado também um curso de técnicos de laboratório, que apresentou o mesmo sentido dos cursos de enfermagem de forma ainda mais especializada, já que se tratava de uma atividade que visava apoiar a execução das diversas disciplinas do curso médico e da rotina de laboratório do hospital, pois os técnicos eram imediatamente contratados para trabalhar nos diversos setores da escola e do hospital, como acontecia com parte do pessoal formado no curso médico e com quase todas as alunas de enfermagem (CNE - Relatório, 1940-44).

A especialização crescente dos serviços do hospital, como a criação do Laboratório Central de Análises Clínicas, a criação de uma revista institucional e outra acadêmica, a instituição de reuniões clínicas, assim como o estabelecimento de diversos prêmios científicos acadêmicos e o incremento de cursos de aperfeiçoamento e extracurriculares, formaram um conjunto de atividades às quais se procurava alinhar e conjugar cada vez mais atividades didáticas. Este conjunto de iniciativas cumpria uma dupla função, primeiro, como forma de legitimação da escola, dentro dos parâmetros e da linguagem esperada para uma instituição científica (Latour, 2000) e, segundo, no que se relaciona ao atendimento hospitalar, como forma de especialização e segmentação dos diversos setores de atenção à saúde.

Impunha-se assim uma prática em que o cuidado com a saúde era cada vez mais sobreposto às prerrogativas de prevenção às doenças, significando que a intervenção médica, no espaço da escola, visava o incremento dos aspectos técnicos da cura e da produtividade no atendimento, entendida como a criação de espaços especializados e criados para este fim, como era o caso do novo hospital.

Ao mesmo tempo, começavam a ser realizados concursos para o preenchimento de algumas cadeiras, que também se diferenciava do momento inicial, quando os docentes eram 'convidados' a com- 
10

Não foi possível precisar exatamente o início das atividades de pesquisa nas dependências da Escola. Há indicação de que as cadeiras de farmacologia e química fisiológica possuíam pesquisa experimental realizada nas dependências da Farmácia do Hospital São Paulo, aproximadamente desde 1940. Estas atividades serão transferidas algum tempo depois para um prédio próprio onde passaram a funcionar os laboratórios da cadeira de farmacologia e química fisiológica, mais tarde bioquímica, que iniciou sua construção em dezembro de 1947 com rendas de exames laboratoriais de doentes particulares e doações de laboratórios farmacêuticos particulares, concluído em agosto de 1956. Estas atividades estiveram intimamente ligadas aos trabalhos iniciais de José Ribeiro do Valle e Leal Prado no Instituto Butantan, como ressaltou Valle: "Graças à compreensão de Dorival Fonseca Ribeiro, atual diretor do Butantan, foi possível salvar o acervo clínico da extinta Seção de Endocrinologia daquele instituto e deste modo prosseguir, na Escola Paulista de Medicina, os trabalhos experimentais $\mathrm{e}$ clínicos lá iniciados" (EPM - Relatório, 1953).

11

Em 21 de janeiro de 1956 a EPM tornou-se uma instituição de ensino superior pública federal pelo decreto $\mathrm{n}^{\mathrm{o}}$ 2.711 no governo de Kubitschek. por os quadros docentes pelos demais componentes da escola, embora os concursos tivessem ainda o caráter pessoal de antes, pois deles participavam apenas candidatos que já trabalhavam na instituição.

O primeiro concurso realizado foi para a cadeira de farmacologia, em 20 de março de 1939, disciplina de $3^{\text {a }}$ série médica. Único candidato inscrito, o professor José Ribeiro do Valle, formado na FMSP em 1932, já trabalhava na escola desde 1934, quando foi convidado para reger a mesma cadeira, ao mesmo tempo que acumulava a função de assistente chefe da Seção de Fisiopatologia do Instituto Butantan, onde também trabalhava outro professor da EPM, José Ignácio Lobo (Valle e Picarelli, 1950). Sua transferência em tempo integral para a EPM incrementou a pesquisa básica nas áreas de farmacologia, química fisiológica e fisiologia. ${ }^{10}$

Penso que neste ponto a EPM iniciou uma nova etapa na sua configuração, caracterizada a partir deste momento pelas relações mais próximas com a administração federal, o que lhe dará novos contornos e diferentes perspectivas, sem, contudo, deixar de revelar influências do primeiro grupo, que imprimiu características próprias à Escola Paulista de Medicina. ${ }^{11}$

\section{Conclusão}

Procurei discutir neste artigo as especificidades da criação de uma nova escola médica em São Paulo, a Escola Paulista de Medicina, no início da década de 1930, como um processo do qual participaram grupos, com expectativas e perspectivas diferentes, mas que convergiram para a discussão de uma ampla gama de questões que atingiam a sociedade naquele momento.

As expectativas contidas na ampliação do acesso ao ensino superior, embutidas na criação de uma escola médica, explicitavam uma nova proposta de desenvolvimento controlado pela compromisso entre parcelas das elites e dos poderes públicos. Por outro lado, a ampliação do acesso à saúde a uma maior parte da sociedade possibilitada pela criação de um hospital de clínicas continha em si também a perspectiva de integrar parcelas da população que não pertenciam àqueles dois grupos, principalmente por representarem um aspecto importante do desenvolvimento econômico nos momentos iniciais da industrialização paulista.

O discurso científico que estava presente nas questões do ensino e da saúde permitiu que se articulasse o tema do bem-estar social ao do progresso, do desenvolvimento da cidade com sua industrialização e da produção de conhecimento com o ordenamento e a organização da sociedade. Assim a criação da EPM, bem como a de outras instituições de ensino no mesmo período, passou a ser uma possibilidade de legitimação destas novas posições, em que o 
12

Em 1994 a EPM foi transformada em Universidade Federal de São Paulo (Unifesp), especializada na área da saúde. suporte da educação e da produção de conhecimento científico permitiu que as elites passassem a aprofundar sua ação sobre o homem e o corpo social, em nome da organização da sociedade em moldes racionais e produtivos.

A EPM e seu hospital de clínicas constituíram passo importante neste processo porque, além dos aspectos específicos do desenvolvimento de um campo particular do conhecimento como a medicina, apresentaram em sua constituição uma forma de encaminhamento em que os esforços da iniciativa privada foram utilizados para a busca de uma parceria com o estado, ajudando a legitimar o lugar da atividade científica na sociedade que é, a grosso modo, recorrente até os dias de hoje. ${ }^{12}$

\section{FONTES}

4.6 .1933

1.4 .1933

1932

Caixa Econômica Federal de São Paulo

Carvalho, Octávio

1938

1937

1914

Conselho Nacional de Educação

Correia Netto,

Alípio et. al.

23.4.1939

Desacordo sobre organização

12.3.1896

Escola de Medicina 10.3.1896

Escola Livre de Sociologia e Política
'A Escola Livre de Sociologia e Política'. Folha da Manhã.

'A questão do curso pré-medico'.

Folha da Noite.

'A reforma da Faculdade de Medicina de São Paulo, o ponto de vista dos alunos'. Folha da Noite.

Oficios expedidos pela secretaria do Conselbo Administrativo. (1933 a 1935).

Discurso inaugural proferido pelo seu diretor dr. Octávio de Carvalho em 15 de julho de 1933. Em Escola Paulista de Medicina, São Paulo, [s.n], 8p.

Collecção das leis e decretos do Estado de São Paulo: 1889-1892. São Paulo, Ed. Official, Imprensa Official do Estado de São Paulo, tomos 1 e 2.

Collecção das leis e decretos do Estado de São Paulo. São Paulo, Ed. Official, Imprensa Official do Estado de São Paulo, tomo XLII.

Collecção das leis e decretos do Estado de São Paulo: 1913. São Paulo, Typografia do Diário Official, tomo XXII.

Relatório da visita a Escola Paulista de Medicina, RJ, 1940-1944, 4 vols.

Festa jubilar do prof. Lemos Torres: discursos.

São Paulo: [s.n.].

São Paulo. OESP.

São Paulo. OESP.

Edição comemorativa dos 64 anos de fundação.

São Paulo, [S.I., s.n.] 
Escola Paulista de Medicina 1953

Escola Paulista de Medicina

Escola Paulista de Medicina

Escola Paulista de Medicina

Escola Paulista de Medicina

Escola Paulista de Medicina 1935

Escola Paulista de Medicina

Escola Paulista de Medicina 1935

Escola Paulista de Medicina 1935

Escola Paulista de Medicina 3.12 .1934

Escola Paulista de Medicina 26.6.1933

Escola Paulista de Enfermagem

Faculdade de Medicina de São Paulo 1991

Faculdade de Medicina de São Paulo/ Universidade de São Paulo 1938

Faculdade de Medicina de São Paulo

Faculdade de Medicina de São Paulo 15.9.1900
Relatório das atividades dos laboratório de Farmacologia e Bioquímica: 1948-1953. São Paulo, EPM/Depto. de saúde do Estado de São Paulo.

ACD - Atas do Conselho Deliberativo

(1.6.1933 a 19.2.1941), 3 vols.

AROEC - Atas de Reuniões Ordinárias e Extraordinárias da Congregação (27.11.1933 a 16.5.1939)

AAGE - Atas das Assembléias Geraes e Extraordinárias

(23.3.1933 a 13.1.1936)

Memorial apresentado ao Exmo. sr. presidente do Departamento Nacional do Café pelo seu dr. diretor dr. Octavio de Carvalho em $1^{\circ}$ de fevereiro de 1936. São Paulo.

Memorial apresentado ao Exmo. sr. dr. diretor do Departamento Nacional de Ensino justificando os pontos do processo de reconhecimento pelo seu dr. diretor dr. Octávio de Carvalho em 5 de outubro de 1935. São Paulo, Estab. Gráfico Cruzeiro do Sul, [s.p.] (Memorial, 20).

Memorial relativo aos debates do Conselho Nacional de Educação em torno do reconhecimento da Escola Paulista de Medicina, coligidos pelo seu dr. diretor Octávio de Carvalho em setembro de 1935. São Paulo, Estab. Gráfico Cruzeiro do Sul, 23p. (Memorial, 18).

Memorial apresentado ao Exmo. sr. Ministro da Educação e Saúde Pública pelo seu dr. diretor Octávio de Carvalho em 25 de julho de 1935. São Paulo, Estab. Gráfico Cruzeiro do Sul, [s.p.] (Memorial, 12).

Memorial apresentado ao Exmo. sr. presidente da República propondo a construção do Hospital São Paulo pelo seu dr. diretor Octávio de Carvalho em 5 de julho de 1935. São Paulo, Estab. Gráfico Cruzeiro do Sul, [s.p.] (Memorial, 11)

Memorial apresentado ao Ministro da Educação e Saúde Pública solicitando o reconhecimento pelo seu diretor dr. Octávio de Carvalho. São Paulo, Estab.Gráfico Cruzeiro do Sul, [s.p.].

Estatutos da Escola Paulista de Medicina. São Paulo, Estab. Gráfico Cruzeiro do Sul, 14p.

EPE. Ata das reuniões do conselho diretor da Escola de Enfermeiras do Hospital São Paulo (12.9.1939 a 30.6.1961).

Centenário de criação da Faculdade de Medicina da Universidade de São Paulo: 1891-1991. São Paulo.

Memória histórica da Faculdade de Medicina da Universidade de São Paulo. São Paulo, Empresa Gráfica da Revista dos Tribunais.

Termos de exame de admissão (jan. 1926 a mar. 1933).

Revista Médica de São Paulo, p. 210. 
Guimarães Filho, A. 1926

Inauguração official 1917

1.6.1933

10.1933

Medeiros, Maurício de 11.8.1910

Meira, Rubião

1913

28.3.1933

11.3.1896

19.7.1933

6.4 .1933

27.3.1933

Pacheco e Silva,

Antônio Carlos

Torres, Álvaro Lemos 1940

Torres, Álvaro Lemos 1937

Torres, Álvaro Lemos 1934

Visita ao Instituto

Rockefeller e ao

dr. Simon Flexner

março de 1909
Da bygiene mental e sua importancia em nosso meio.

Doutoramento em medicina, São Paulo, Faculdade de Medicina de São Paulo.

Início dos cursos superiores. Memorial do reitor aos governos federal e estadual. Abertura e encerramento dos annos lectivos. Comemorações e recepções. Documentos e notas, Casa Duprat, São Paulo, Arquivo do Estado de São Paulo, vol. 1.

'Manifesto de fundação da Escola Paulista de Medicina' Folha da Noite.

'Manifesto'. Folha da Noite. 29.

'A questão do ensino'.

Correio Paulistano.

Perfis e luctas. São Paulo, Estab.

Gráfico Universal.

'Muitos candidatos para poucas vagas'. Folha da Noite.

‘Não chegaram a accordo’. São Paulo, OESP.

'O êxito alcançado em S. Paulo pela Escola de Sociologia e Politica'. São Paulo, Folba da Noite.

'O que pretendem os alumnos do curso pré-medico é baseado em argumentos claros e positivos'. Folha da Noite.

‘Os candidatos do curso Pré-medico querem seu desdobramento’. Folha da Noite.

'Os exames vestibulares na Faculdade de Medicina'. Folha da Noite.

Iniciação médica: aula inaugural dos cursos da Escola Paulista de Medicina proferida em 15 de julbo de 1933. São Paulo, [s.n], 1933.

O problema hospitalar em São Paulo: discurso pronunciado por ocasião da inauguração do Hospital São Paulo, da Escola Paulista de Medicina, em 4 de outubro de 1940. São Paulo, Estab. Gráfico Cruzeiro do Sul.

Curriculum vitae: apresentado a comissão julgadora para revalidação do título de livre-docente de clínica médica da Faculdade de Medicina da USP. São Paulo, Ed. Limitada.

'Do ensino da clínica: lição inaugural dos cursos da Escola Paulista de Medicina'. São Paulo : [s.n.].

Gazeta Clinica, anno VII, p. 3. 


\section{REFERÊNCIAS BIBLIOGRÁFICAS}

Albernaz,

Paulo Mangabeira 1968

Almeida, Marta 1998

Álvaro, Moacyr E. 1937

Antonacci, Maria Antonieta $M$. 1993

Benchimol, Jaime Larry e Teixeira, Luis Antonio 1993

Bertarelli, Ernesto 20.6.1910

Carneiro, Glauco 1986

De Decca, E. 1997

De Lorenzo, Helena Carvalho e Costa, Wilma Peres da 1997

Edler, Flávio Coelho 1992

Gomes, Angela de Castro

1999

Gomes, Angela de Castro (org.) 2000

Gomes, Mara Helena de Andréa 1992

Gualtieri, Regina Cândida E. 1994

Guimarães, Antonio da Palma S. d.

Hochman, Gilberto 1998

Lacaz, Carlos da Silva e Mazzieri, Berta Ricardo
A Escola Paulista de Medicina. São Paulo, Empresa Gráfica da Revista dos Tribunais.

A República dos invisiveis: Emilio Ribas, microbiologia e saúde pública em São Paulo (1898-1917). Dissertação de Mestrado, São Paulo, FFLCH/USP, (mimeo.)

'Organização scientifica do trabalho em medicina'. Em Instituto de Organização Racional do Trabalho (IDORT), Racionalização e medicina. São Paulo,Empresa Gráfica da Revista dos Tribunais, pp. 7-14.

A vitória da razão: O Idort e a sociedade paulista.

São Paulo, Marco Zero.

Cobras, largatos \& outros bichos: uma bistória comparada dos institutos Oswaldo Cruz e Butantan. Rio de Janeiro, Ed. UFRJ.

História pequena da medicina hoje. OESP.

O poder da misericórdia: a Irmandade da Santa Casa na história social e política da cidade de São Paulo (1560-1985). São Paulo, Press Grafic, 2 vols.

'Revisando a industrialização brasileira. Onde a memória histórica trai sem constrangimentos a história'. Revista Resgate, nº. 7, pp. 113-36.

A década de 1920 e as origens do Brasil moderno.

São Paulo, Fundação Ed. da Unesp.

As reformas no ensino médico e a profissionalização da medicina na corte do Rio de Janeiro (1854-1884). Dissertação de mestrado, São Paulo, FFLCH/USP. (mimeo.)

'Ideologia e trabalho no Estado Novo'Em Dulce Chaves Pandolfi (org.) Repensando o Estado Novo. Rio de Janeiro, Editora da FGV.

Capanema: o ministro e seu ministério.

Rio de Janeiro. Editora da FGV.

Tradição e progresso técnico: a medicina e o ensino médico na Escola Paulista de Medicina. Dissertação de mestrado, São Paulo, PUC. (mimeo.)

O Instituto Butantan e a saúde pública (São Paulo: 1901-1927). Dissertação de mestrado, São Paulo, Faculdade de Educação da USP. (mimeo.)

Arnaldo Vieira de Carvalbo: biografia e crítica. São Paulo, Governo do Estado de São Paulo, vols. 1 e 2.

A era do saneamento: as bases da política de saúde pública no Brasil. São Paulo, Hucitec.

A Faculdade de Medicina e a USP. São Paulo, Edusp. 
Latour, Bruno

2000

Marinho,

Gabriela S. M. C. 1993

Meira, Rubião 1913

Miceli, Sergio (org.) 1989

Monarhca, Carlos 1989

Mota, Carlos

Guilherme e Capelato,

Maria Helena

1981

Nadai, Elza

1987

Prado, Antonio

de Almeida

1954

Ribeiro, Maria

Alice Rosa

1993

Sadi, Afiz e Freitas,

Divaldo Gaspar

1995

Salles, Maria do

Rosário Rolfsen

1997

Sevcenko, Nicolau 1992

Silvia, Márcia

Regina Barros da 1998

Silva, Marina C. V. 1994

Teixeira, Luiz Antonio 1995

Tellatorolli Jr., R. 1996

Valle, José Ribeiro 1961

Valle, José Ribeiro e

Guimarães, Cendy 1961

Valle, José Ribeiro e Picarelli, Zuleika P.
Ciência em ação.

São Paulo, Editora da Unesp.

O papel da Fundação Rockefeller na organização do ensino e da pesquisa na Faculdade de Medicina de São Paulo. Dissertação de mestrado, São Paulo, Instituto de Geociências da Unicamp. (mimeo.)

Perfis e lutas.

São Paulo, Estabelecimento Graphico Universal.

Histórias das ciências sociais no Brasil.

São Paulo, Vértice/Ed. Revista dos Tribunais.

A reinvenção da cidade e da multidão: dimensões da modernidade brasileira: a Escola Nova. São Paulo, Cortez.

História da Folha de São Paulo (1921-1981).

São Paulo, Cia. Brasileira de Impressão e Propaganda.

Ideologia do progresso e ensino superior (São Paulo 1891-1934).

São Paulo, Loyola.

'Quatro séculos de medicina na cidade de São Paulo'.

Em Ensaios paulistas. São Paulo, Anhembi.

História sem fim... inventário da saúde pública.

São Paulo, Unesp.

O ensino médico em São Paulo anteriormente à fundação da Paulista.

São Paulo, Ed. Comercial Safady Limitada.

Médicos italianos em São Paulo (1890-1930).

São Paulo, Sumaré. Série Imigração.

O orfeu extático na metrópole: São Paulo sociedade e cultura nos frementes anos 20. São Paulo, Companhia das Letras.

Construindo uma instituição: Escola Paulista de Medicina (1933-1956.

Dissertação de mestrado, São Paulo, FFLCH/USP.

Da maria fumaça à fumaça das fábricas. A Escola Livre de Sociologia de São Paulo (1922-1940). Tese de doutoramento, São Paulo, Faculdade de Educação da USP. (mimeo.)

Ciência e saúde na terra dos bandeirantes: a trajetória do Instituto Pasteur de São Paulo no período de 1903-1916. Rio de Janeiro, Editora Fiocruz.

Poder e saúde: as epidemias e a formação dos serviços de saúde em São Paulo. São Paulo, Unesp.

'Homens e instituições: a obra científica e social de Eduardo Guimarães'. Ciência e Cultura, vol. 13, no 2 .

Vida e obra do dr. Eduardo Guimarães.

Rio de Janeiro, Monografia do Instituto Brasileiro de História da Medicina.

A endocrinologia no Instituto Butantan (1934-1949).

(mimeo.), [1950], $50 \mathrm{p}$. 